\title{
PENGARUH MODEL PEMBELAJARAN ARTIKULASI TERHADAP HASIL BELAJAR SISWA KELAS XI DI MA PATRA MANDIRI PALEMBANG
}

\author{
Oleh: Nurjannah ${ }^{1}$, Yasir Arafat $^{2}$, M. Toyib ${ }^{3}$ \\ nungnungnung00@gmail.com ${ }^{1}$, yasirarafat@univpgri-palembang.ac.id ${ }^{2}$, \\ muhammad toyib38@yahoo.com ${ }^{3}$ \\ (Program Studi Pendidikan Akuntansi, FKIP Universitas PGRI Palembang)
}

\begin{abstract}
Abstrak-Tujuan dalam penelitian ini adalah untuk mengetahui ada pengaruh penerapan model pembelajaran artikulasi terhadap hasil belajar siswa pada mata pelajaran Ekonomi kelas X di MA Patra Mandiri Palembang Tahun Pelajaran 2020/2021. Metode penelitian yang digunakan adalah metode eksperimen dengan pendekatan kuantitatif. Hasil penelitian menunjukkan bahwa ada pengaruh penerapan model pembelajaran artikulasi terhadap hasil belajar siswa pada mata pelajaran Ekonomi kelas XI di MA Patra Mandiri Palembang tahun pelajaran 2020/2021. Hasil ini dibuktikan nilai $t_{\text {hitung }}(10,25)>t_{\text {tabel }}(1,67203)$. Selain itu, nilai rata-rata siswa kelas eskperimen yang menerapkan model pembelajaran artikulasi yaitu 81,5 dan nilai rata-rata siswa kelas kontrol yang menerapkan metode konvensional yaitu 63,81 dimana hal tersebut menunjukkan bahwa model pembelajaran artikulasi lebih baik dibandingkan metode konvensional.
\end{abstract}

Kata Kunci : Model Pembelajaran Airtikulasi, Hasil Belajar

\begin{abstract}
The purpose of this study was to see the effect of the application of the articulation learning model on student learning outcomes in class X Economics at MA Patra Mandiri Palembang for the 2020/2021 academic year. The research method used is an experimental method with a quantitative approach. The results showed that there was an effect of the articulation learning model on student learning outcomes in the XI class of Economics at MA Patra Mandiri Palembang in the 2020/2021 academic year. This result is evidenced by the value of $t$ (10.25)> t table (1.67203). In addition, the mean score of the experimental class students who applied the articulation learning model was 81.5 and the average score of the control class students who applied the conventional method was 63.81, which indicated that the articulation learning model was better than the conventional method.
\end{abstract}

Keywords: Airticulation Learning Model, Learning Outcomes

\section{PENDAHULUAN}

Menurut Prasetia (2016:50)

"Ekonomi adalah ilmu tentang alokasi sumber daya pada beranekaragam keinginan manusia." Dengan demikian, ilmu ekonomi yaitu ilmu yang mempelajari perilaku manusia dalam melakukan aktivitas ekonomi dengan atau tanpa uang.

Tujuan ilmu ekonomi ini adalah untuk meramalkan berbagai peristiwa ekonomi dan untuk membuat berbagai kebijakan yang 
akan mencegah atau mengoreksi berbagai masalah seperti pengangguran, inflasi, atau pemborosan dalam perekonomian. Menurut Prasetia (2016:50) "Ekonomi adalah ilmu tentang alokasi sumber daya pada beranekaragam keinginan manusia." Dengan demikian, ilmu ekonomi yaitu ilmu yang mempelajari perilaku manusia dalam melakukan aktivitas ekonomi dengan atau tanpa uang.

Dilihat dari sisi pendidikan, ekonomi merupakan salah satu mata pelajaran yang dipelajari oleh siswa, mulai dari sekolah dasar pada mata pelajaran IPS, sekolah menengah pertama pada mata pelajaran IPS Terpadu, dan sekolah menengah atas, bahkan sampai ke jenjang perguruan tinggi.

Hasil pengamatan peneliti di MA Patra Mandiri Palembang diketahui bahwa sarana dan prasarana belajar sudah memadai. Hal ini didapat peneliti lihat dari tersedianya alat dan media belajar, seperti tersedianya buku paket siswa dan guru, adanya kliping mata uang Indonesia dan beberapa negara di dunia, dan lainnya. Selain tersedianya sarana dan prasarana belajar, guru di MA Patra Mandiri Palembang sebagian besar atau 31 guru merupakan guru tetap Yayasan Patra Mandiri dan hanya 8 orang guru tidak tetap. Keuntungan dari guru tetap Yayasan adalah diterimanya insentif di luar gaji yang dibayarkan oleh Yayasan tersebut, sehingga kebutuhannya bisa dikatakan terpenuhi. Untuk penyelesaian administrasi mengajar, guru tetap maupun guru tidak tetap di MA Patra Mandiri Palembang disediakan 1 unit komputer beserta alat print dan kertas sehingga guru tidak lagi mengeluarkan biaya untuk melengkapi administrasi dalam mengajar.

Berdasarkan hasil wawancara dengan guru mata pelajaran ekonomi yang mengajar di kelas XI MA Patra Mandiri Palembang diketahui bahwa materi konsep dasar ilmu ekonomi dipelajari pada Semester 1 (gazal). Dalam proses pembelajarannya, guru masih menggunakan metode konvensional (metode ceramah). Hal ini dapat diketahui saat peneliti melakukan wawancara kepada guru mata pelajaran ekonomi yang mengajar di kelas XI MA Patra Mandiri Palembang pada hari Senin tanggal 13 Juli 2020. Guru juga menjelaskan bahwa siswa mencatat dan mendengarkan penjelasan guru. Pada akhirnya, guru menjelaskan bahwa sebagian siswa masih terlihat belum mengerti tentang materi yang disampaikan oleh guru. Selain itu, berdasarkan data hasil belajar siswa (tahun pelajaran 2019/2020) yang diperoleh dari guru mata pelajaran ekonomi kelas XI MA Patra Mandiri Palembang diketahui bahwa rata-rata hasil belajar siswa belum mencapai Kriteria Ketuntasan Minimal (KKM) yaitu 75,00. 
Selain itu, guru juga menjelaskan bahwa permasalahan lainnya adalah pemahaman siswa tentang ekonomi sebagai ilmu, diasumsikan sebagai ilmu hafalan dan tidak ada manfaatnya dalam kehidupan keseharian. Permasalahan-permasalahan tersebut bisa diatasi dengan menerapkan pembelajaran yang inovatif, salah satunya adalah dengan menerapkan model pembelajaran artikulasi. Model pembelajaran artikulasi dapat diartikan sebagai upaya pendidik untuk mengikutsertakan peserta didik dalam kegiatan pembelajaran. Model pembelajaran artikulasi mengandung arti ikut sertanya peserta didik di dalam program model pembelajaran artikulasi. Keikutsertaan peserta didik itu diwujudkan dalam tiga tahapan kegiatan pembelajaran yaitu perencanaan program, pelaksanaan, dan penilaian kegiatan pembelajaran (Sudjana, 2000:155). Model pembelajaran artikulasi adalah pembelajaran yang sangat tepat sebagai pembelajar para ahli dalam keadaan yang tidak teratur atau ahli dalam memecahkan masalah (Pow, 2007:19).

Pembelajaran atau ungkapan yang lebih dikenal sebelumnya "pengajaran" adalah upaya untuk membelajarkan siswa (Majid, 2008:11). Pembelajaran menurut Corey adalah suatu proses dimana lingkungan seseorang secara disengaja dikelola untuk memungkinkan ia turut serta dalam tingkah laku tertentu dalam kondisikondisi khusus atau menghasilkan respons terhadap situasi tertentu.

Menurut Suryono (2010:1), ada beberapa indikator dalam model pembelajaran artikulasi yaitu (1) adanya keterlibatan emosional dan mental peserta didik (2) adanya keterlibatan peserta didik untuk memberikan kontribusi dalam pencapaian tujuan (3) dalam kegiatan belajar terdapat hal yang menguntungkan peserta didik.

Rahman

menjelaskan bahwa kelebihan model pembelajaran artikulasi yaitu materi yang disampaikan kepada siswa lebih jelas serta konkrit, dapat melatih siswa menjadi seorang guru karena siswa diberi kesempatan untuk menjelaskan materi kepada siswa lainnya, sedangkan kekurangannya adalah memerlukan waktu yang banyak dan sedikitnya materi yang bisa disampaikan karena keterbatasan waktu.

Menurut Purwanto (2016:44), Hasil belajar dapat dijelaskan dengan memahami dua kata yang membentuknya, yaitu hasil dan belajar. Pengertian hasil (product) menunjuk pada suatu perolehan akibat dilakukannya suatu aktivitas atau proses yang mengakibatkan berubahnya input secara fungsional. Selanjutnya Sudjana (2014:45) mendefinisikan hasil belajar siswa pada hakikatnya adalah perubahan tingkah laku sebagai hasil belajar dalam pengertian yang lebih luas 
mencakup bidang kognitif, afektif, dan psikomotorik.

Tujuan ilmu ekonomi ini adalah untuk meramalkan berbagai peristiwa ekonomi dan untuk membuat berbagai kebijakan yang akan mencegah atau mengoreksi berbagai masalah seperti pengangguran, inflasi, atau pemborosan dalam perekonomian. Menurut Prasetia (2016:50) "Ekonomi adalah ilmu tentang alokasi sumber daya pada beranekaragam keinginan manusia." Dengan demikian, ilmu ekonomi yaitu ilmu yang mempelajari perilaku manusia dalam melakukan aktivitas ekonomi dengan atau tanpa uang.

\section{METODE PENELITIAN}

Metode penelitian merupakan rangkaian cara atau kegiatan pelaksanaan penelitian yang didasari oleh asumsi-asumsi dasar dasar, pandangan-pandangan filosofis dan ideologis, pertanyaan dan isu-isu yang dihadapi (Sukmadinata, 2012:52). Sehubungan dengan masalah yang akan diteliti, maka penelitian ini menggunakan metode eksperimen dengan pendekatan kuantitatif. Metode eksperimen dapat diartikan sebagai metode penelitian yang digunakan untuk mencari pengaruh perlakuan tertentu terhadap yang lain dalam kondisi yang terkendalikan (Sugiyono, 2010:107).

Teknik pengumpulan data yang akan digunakan dalam penelitian ini adalah sebagai berikut:

\section{Teknik Tes}

Menurut Riyanto (2010:103), tes adalah serentetan atau latihan yang digunakan untuk mengukur keterampilan, pengetahuan, sikap, intelegensi, kemampuan atau bakat yang dimiliki oleh individu atau kelompok. Tes yang digunakan dalam penelitian ini berupa soal pilihan ganda berjumlah 20 soal, yang mana memiliki tingkat kesukaran yaitu mudah, sedang dan sulit. yang sebelumnya dilakukan pengujian validitas dan reliabilitas tes tersebut. Di mana tes tersebut akan diberikan kepada Siswa di Kelas Eksperimen dan Kontrol, dan soal tes tersebut sudah valid dan reliabel.

\section{Teknik Dokumentasi}

Menurut Arikunto (2014:274), metode dokumentasi yaitu mencari data mengenai hal-hal atau variabel yang berupa catatan, transkrip, buku, surat kabar, majalah, prasasti, notulen, rapat, legger, agenda, dan sebagainya. Teknik dokumentasi dalam penelitian ini digunakan untuk mengetahui keadaan sekolah, jumlah siswa, dan perangkat pembelajaran seperti RPP, silabus, dan kegiatan belajar mengajar.

\section{Teknik Observasi}

Menurut Arikunto (2014:263), observasi merupakan teknik pengamatan langsung terhadap suatu objek yang ada di lingkungan yang sedang berlangsung meliputi berbagai aktivitas perhatian terhadap kajian objek dengan menggunakan 
pengindraan. Dalam penelitian ini, teknik observasi digunakan untuk mengetahui keadaan sarana dan prasarana di MA Patra Mandiri Palembang.

Untuk mengetahui besarnya sumbangan variabel $\mathrm{X}$ terhadap variabel $\mathrm{Y}$, peneliti menggunakan rumus sebagai berikut:

$K P=r^{2} \times 100 \%$ (Pramika, 2020:30).

\section{HASIL DAN PEMBAHASAN}

Berikut ini adalah hasil posttest (tes akhir) siswa kelas XI.IIS.3 (kelas kontrol).

Tabel 1. Nilai Posttest Siswa Kelas Kontrol

\begin{tabular}{|c|c|c|}
\hline No. & Inisial Siswa & Nilai Posttest \\
\hline 1 & AS & 75 \\
\hline 2 & AWN & 65 \\
\hline 3 & AAR & 60 \\
\hline 4 & $\mathrm{AF}$ & 75 \\
\hline 5 & $\mathrm{AD}$ & 65 \\
\hline 6 & FYL & 75 \\
\hline 7 & FA & 65 \\
\hline 8 & HY & 60 \\
\hline 9 & Hrf & 70 \\
\hline 10 & HA & 65 \\
\hline 11 & IP & 65 \\
\hline 12 & LM & 70 \\
\hline 13 & MD & 65 \\
\hline 14 & MFD & 70 \\
\hline 15 & MR & 60 \\
\hline 16 & Mzs & 55 \\
\hline 17 & Mrd & 60 \\
\hline 18 & MDP & 70 \\
\hline 19 & MI & 60 \\
\hline 20 & NP & 70 \\
\hline 21 & RR & 50 \\
\hline 22 & SA & 65 \\
\hline 23 & SAf & 65 \\
\hline 24 & $\mathrm{CR}$ & 60 \\
\hline 25 & $\mathrm{TF}$ & 50 \\
\hline 26 & Yds & 60 \\
\hline 27 & WRS & 60 \\
\hline 28 & $\mathrm{ZJ}$ & 60 \\
\hline \multirow[t]{5}{*}{29} & ZJA & 40 \\
\hline & JUMLAH & 1830 \\
\hline & RATA-RATA & 63,10 \\
\hline & NILAI TERBESAR & 75 \\
\hline & NILAI TERKECIL & 40 \\
\hline
\end{tabular}

Sumber: Data Primer Diolah, 2019 
Berdasarkan Tabel 1 tersebut dapat diketahui rata-rata nilai posttest sebesar 63,10 dengan nilai tertinggi 75 dan terendah 40 .
Berikut ini adalah nilai posttest (tes akhir) siswa kelas XI.IIS.2 (kelas eksperimen).

Tabel 2. Nilai Posttest Siswa Kelas Eksperimen

\begin{tabular}{|c|c|c|}
\hline No. & Nama Siswa & Nilai Posttest \\
\hline 1 & Abd & 90 \\
\hline 2 & AMA & 80 \\
\hline 3 & $\mathrm{AN}$ & 90 \\
\hline 4 & AA & 85 \\
\hline 5 & AP & 80 \\
\hline 6 & Ans & 85 \\
\hline 7 & Awld & 80 \\
\hline 8 & $\mathrm{CS}$ & 85 \\
\hline 9 & DDP & 80 \\
\hline 10 & PA & 85 \\
\hline 11 & Fnny & 75 \\
\hline 12 & FD & 80 \\
\hline 13 & HA & 75 \\
\hline 14 & JA & 80 \\
\hline 15 & KBS & 75 \\
\hline 16 & Lck & 80 \\
\hline 17 & MAA & 80 \\
\hline 18 & Mhd & 80 \\
\hline 19 & Mrt & 80 \\
\hline 20 & MP & 70 \\
\hline 21 & MR & 80 \\
\hline 22 & NO & 80 \\
\hline 23 & Nvr & 75 \\
\hline 24 & PR & 80 \\
\hline 25 & Ral & 80 \\
\hline 26 & RDR & 75 \\
\hline 27 & $\mathrm{SA}$ & 80 \\
\hline 28 & SA & 80 \\
\hline 29 & $\mathrm{~T}$ & 75 \\
\hline \multirow[t]{5}{*}{30} & $\mathrm{ZA}$ & 65 \\
\hline & JUMLAH & 2385 \\
\hline & RATA-RATA & $\mathbf{7 9 , 5 0}$ \\
\hline & NILAI TERBESAR & 90 \\
\hline & NILAI TERKECIL & 65 \\
\hline
\end{tabular}

Sumber: Data Primer Diolah, 2019

Berdasarkan Tabel 2 tersebut posttest (tes akhir) setelah diajarkan dapat diketahui rata-rata nilai menggunakan model pembelajaran 
artikulasi sebesar 79,50 dengan nilai terbesar 90 dan nilai terkecil 65 .

Bersarnya pengaruh model pembelajaran artikulasi terhadap hasil belajar siswa peneliti menggunakan rumus yaitu $\mathrm{KP}=\mathrm{r}^{2} \mathrm{x}$ $100 \%$. Untuk memudahkan perhitungannya peneliti membuat tabel penolong sebagai berikut:

Tabel 3. Data Tes Hasil Belajar Siswa Kelas Eksperimen

\begin{tabular}{|c|c|c|c|c|c|}
\hline No & $\begin{array}{c}\text { Data Pretest } \\
\text { (X) }\end{array}$ & $\begin{array}{l}\text { Data Posttest } \\
\text { (Y) }\end{array}$ & $\mathrm{X}^{2}$ & $\mathrm{Y}^{2}$ & X.Y \\
\hline 1 & 70 & 90 & 4900 & 8100 & 6300 \\
\hline 2 & 65 & 80 & 4225 & 6400 & 5200 \\
\hline 3 & 75 & 90 & 5625 & 8100 & 6750 \\
\hline 4 & 60 & 85 & 3600 & 7225 & 5100 \\
\hline 5 & 60 & 80 & 3600 & 6400 & 4800 \\
\hline 6 & 65 & 85 & 4225 & 7225 & 5525 \\
\hline 7 & 65 & 80 & 4225 & 6400 & 5200 \\
\hline 8 & 70 & 85 & 4900 & 7225 & 5950 \\
\hline 9 & 65 & 80 & 4225 & 6400 & 5200 \\
\hline 10 & 65 & 85 & 4225 & 7225 & 5525 \\
\hline 11 & 50 & 75 & 2500 & 5625 & 3750 \\
\hline 12 & 65 & 80 & 4225 & 6400 & 5200 \\
\hline 13 & 50 & 75 & 2500 & 5625 & 3750 \\
\hline 14 & 65 & 80 & 4225 & 6400 & 5200 \\
\hline 15 & 60 & 75 & 3600 & 5625 & 4500 \\
\hline 16 & 65 & 80 & 4225 & 6400 & 5200 \\
\hline 17 & 65 & 80 & 4225 & 6400 & 5200 \\
\hline 18 & 70 & 80 & 4900 & 6400 & 5600 \\
\hline 19 & 70 & 80 & 4900 & 6400 & 5600 \\
\hline 20 & 45 & 70 & 2025 & 4900 & 3150 \\
\hline 21 & 65 & 80 & 4225 & 6400 & 5200 \\
\hline 22 & 60 & 80 & 3600 & 6400 & 4800 \\
\hline 23 & 55 & 75 & 3025 & 5625 & 4125 \\
\hline 24 & 65 & 80 & 4225 & 6400 & 5200 \\
\hline 25 & 60 & 80 & 3600 & 6400 & 4800 \\
\hline 26 & 50 & 75 & 2500 & 5625 & 3750 \\
\hline 27 & 65 & 80 & 4225 & 6400 & 5200 \\
\hline 28 & 65 & 80 & 4225 & 6400 & 5200 \\
\hline 29 & 50 & 75 & 2500 & 5625 & 3750 \\
\hline 30 & 45 & 65 & 2025 & 4225 & 2925 \\
\hline$\Sigma$ & 1845 & 2385 & 115225 & 190375 & 147650 \\
\hline
\end{tabular}

Sumber: Data Primer Diolah, 2019

Penelitian dilakukan di MA judul "Pengaruh Penerapan Model Patra Mandiri Palembang dengan Pembelajaran Artikulasi Terhadap 
Hasil Belajar Siswa Pada Mata Pelajaran Ekonomi Kelas XI di MA Patra Mandiri Palembang Tahun Pelajaran 2020/2021". Tujuan dari penelitian ini adalah untuk mengetahui pengaruh penerapan model pembelajaran artikulasi terhadap hasil belajar siswa pada mata pelajaran Ekonomi kelas XI di MA Patra Mandiri Palembang tahun Pelajaran 2020/2021. Dalam penelitian ini, alat pengumpul data berupa instrument tes, maka peneliti melakukan analisis data tes tersebut. Analisis data dilakukan dengan menggunakan uji-t yang terdiri dari uji normalitas data dan uji homogenitas data. Uji normalitas data dilakukan untuk mengetahui normal atau tidaknya suatu penyebaran data, kemudian uji homogenitas data diperlukan untuk membuktikan persamaan variansi kelompok sampel.

Berdasarkan hasil perhitungan yang didapat untuk hasil posttest, baik kelas kontrol maupun kelas eksperimen diperoleh nilai SK posttest kelas kontrol sebesar 0,12 dan nilai SK posttest kelas eksperimen sebesar $-0,14$. Nilai SK yang diperoleh dari data posttest kelas kontrol maupun kelas eksperimen terletak antara (-1) dan (1) sehingga dapat dikatakan bahwa data posttest kelas kontrol maupun kelas eksperimen dapat dikatakan berdistribusi normal. Untuk hasil perhitungan uji homogenitas data diperoleh $\mathrm{X}_{\text {hitung }}^{2}=-144,488$ dan
$\mathrm{X}_{\text {tabel }}^{2}=3,84$ dan diketahui syarat homogen: $X^{2}{ }_{\text {hitung }}<X_{\text {tabel }}^{2}(-144,488$ $<3,84)$. Dari hasil tersebut dapat disimpulkan bahwa, sampel berasal dari populasi yang sama. Jadi data penelitian yang berasal dari hasil posttest mengikuti distribusi normal dan homogen.

Setelah pengujian normalitas data dan homogenitas data dilakukan, data tersebut dinyatakan terdistribusi normal dan varians dalam penelitian ini bersifat homogen, maka tahap berikutnya adalah melakukan pengujian hipotesis penelitian dengan menggunakan statistik parametris, yaitu menggunakan rumus Uji-t dengan kriteria pengujian terima. Dari hasil analisa data menunjukkan bahwa hasil tes akhir untuk hasil posttest diperoleh $t_{\text {hitung }}=10,25$ dan $\mathrm{t}_{\text {tabel }}$ dengan taraf nyata $5 \%$ dan $\mathrm{dk}=$ 57 diperoleh $t_{\text {tabel }}=1,67203$. Dengan demikian, ternyata $t_{\text {hitung }}>t_{\text {tabel }}$ $(10,25>1,67203)$ maka dapat ditarik kesimpulan "Ada pengaruh penerapan model pembelajaran artikulasi terhadap hasil belajar siswa pada mata pelajaran Ekonomi kelas XI di MA Patra Mandiri Palembang tahun pelajaran 2020/2021" atau hipotesis Ha diterima kebenarannya. Besarnya sumbangan variabel $\mathrm{X}$ terhadap variabel Y adalah $83,73 \%$.

Hasil penelitian Puspitasari, Maasawet, dan Fatmawati (2016) menunjukkan bahwa terdapat pengaruh penggunaan model model pembelajaran artikulasi dapat 
mempengaruhi hasil belajar siswa. Hal ini dapat dilihat dari 1) pembelajaran sudah berpusat pada peserta didik; 2) pembelajaran ini dapat mengembangkan kreatifitas peserta didik; 3) model pembelajaran artikulasi dapat menciptakan kondisi yang menyenangkan dan menantang bagi peserta didik; 4) kemudian model pembelajaran artikulasi juga memiliki nilai etika, estetika, logika dan kinestika, sehingga peserta didik mempunyai pengalaman belajar yang beragam.

Kegiatan pembelajaran mengembangkan kemampuan untuk mengetahui, memahami, melakukan sesuatu, hidup dalam kebersamaan, dan mengaktualisasikan diri. Dengan demikian, kegiatan pembelajaran perlu : 1) berpusat pada peserta didik; 2) mengembangkan kreatifitas peserta didik; 3) menciptakan kondisi yang menyenangkan dan menantang; 4) bermuatan nilai, etika, estetika, logika dan kinestika, dan 5) menyediakan pengalaman belajar yang beragam.

Berdasarkan teori tersebut, dalam penelitian ini peneliti telah melakukan semua kegiatan pada model pembelajaran artikulasi seperti 1) pembelajaran berpusat pada peserta didik; 2) dapat mengembangkan kreatifitas peserta didik; 3) menciptakan kondisi yang menyenangkan dan menantang; 4) bermuatan nilai, etika, estetika, logika dan kinestika, dan 5) menyediakan pengalaman belajar yang beragam. Setelah melakukan semua kegiatan tersebut, maka dapat disimpulkan bahwa 1) model pembelajaran artikulasi dapat mendorong siswa untuk meningkatkaan inisiatif dan partisipasi; 2) Siswa tidak mendominasi pembicaraan atau diam sama sekali pada saat penerapan model pembelajaran artikulasi; 3) dalam pelaksanaan model pembelajaran artikulasi siswa menjadi aktif; 4) kemampuan siswa berkomunikasi meningkat setelah diterapkan model pembelajaran artikulasi; 5) model pembelajaran artikulasi membuat siswa mau mengungkapkan pendapatnya; 6) siswa saling mendengarkan, memberikan masukan, dan keterbukaan terhadap kritik pada saat menerapkan model pembelajaran artikulasi; dan 7) model pembelajaran artikulasi dapat mengajarkan siswa untuk menghargai pendapat orang lain.

\section{KESIMPULAN}

Berdasarkan hasil penelitian yang telah dilakukan dapat ditarik kesimpulan bahwa ada pengaruh penerapan model pembelajaran artikulasi terhadap hasil belajar siswa pada mata pelajaran Ekonomi kelas XI di MA Patra Mandiri Palembang tahun pelajaran 2020/2021. Hasil ini dibuktikan nilai $t_{\text {hitung }}(10,25)>t_{\text {tabel }}$ $(1,67203)$. Selain itu, nilai rata-rata siswa kelas eskperimen yang menerapkan model pembelajaran 
artikulasi yaitu 81,5 dan nilai ratarata siswa kelas kontrol yang menerapkan metode konvensional yaitu 63,81 dimana hal tersebut menunjukkan bahwa model pembelajaran artikulasi lebih baik dibandingkan metode konvensional.

\section{DAFTAR PUSTAKA}

Pramika, Depi. (2020). Booklet Statistik Penelitian. Palembang: Bening Media Publishing.

Prasetia, Ferry. (2016). Modul Ekonomi Publik Bagian V Teori Pengeluaran Pemerintah. Malang: Fakultas Ekonomi dan Bisnis Brawijaya.

Purwanto. (2016). Evaluasi Hasil Belajar. Yogyakarta: Pustaka Pelajar.

Rahman. (2011). Model Mengajar dan Bahan Pembelajaran. Bandung: Alqa Prisma Interdelta.

Riyanto, Y. (2010). Metodologi Penelitian Pendidikan. Surabaya: Penerbit SIC.

Sudjana, Nana. (2014). Dasar-Dasar Proses Belajar Mengajar. Bandung: Sinar Baru.

Sugiyono. (2010). Metode Penelitian Kualitatif, Kuantitatif, $R \& D$. Bandung; Alfabeta.

Sukmadinata, NS. (2012). Metode Penelitian Pendidikan. Bandung: Alfabeta.

Suryono, Yoyon. (2010) model pembelajaran. (Online) (http://yoyonsuryono.wordpres s.com 12/02/2010, diakses tanggal 19 Maret 2019) (Rujukan dari Internet) 